\title{
Detecting Extremity Ischemia Due to Extracorporeal Membrane Oxygenation Cannula Placement with Near-Infrared Spectroscopy
}

\author{
Feng FENG ${ }^{1}{ }^{*}$, Joshua D. OWEN ${ }^{1}$, Bhaswati MANISH ${ }^{1}$, Kenton EWING ${ }^{2}$ and Nicolas CONTRYMAN ${ }^{2}$ \\ ${ }^{1}$ Department of Pathology, Nebraska Methodist College, USA \\ ${ }^{2}$ CRNA at Anesthesiology Department of CHI Health Creighton University Medical Center, USA \\ *Corresponding author: Feng Feng, Department of Pathology, Nebraska Methodist College, USA \\ To Cite This Article: Feng FENG, Joshua D. OWEN, Bhaswati MANISH, Kenton EWING, Nicolas CONTRYMAN. Detecting Extremity Ischemia Due \\ to Extracorporeal Membrane Oxygenation Cannula Placement with Near-Infrared Spectroscopy. Am J Biomed Sci \& Res. 2021 - 14(2). AJBSR. \\ MS.ID.001972. DOI: 10.34297/AJBSR.2021.14.001972.
}

Received: 眥August 11, 2021; Published: 些 September 21, 2021

\begin{abstract}
Abbreviations: WHO: World Health Organization; ECMO: Extracorporeal Membrane Oxygenation; ARDS: Acute Respiratory Distress Syndrome; ICU: Intensive Care Unit; HER: Electronic Health Records; NIRS: Near-Infrared Spectroscopy
\end{abstract}

\section{Introduction}

World Health Organization (WHO) interim guidelines recommend administering extracorporeal membrane oxygenation (ECMO) with acute respiratory distress syndrome (ARDS) related to coronavirus disease 2019 (COVID-19) 2020) World Health Organization [1]. ECMO consists of an external blood pump, oxygenator, lines, and cannulas that connect to the patient's vascular system. Typically, there is one cannula placed in the femoral vein, and one placed in the internal jugular vein or femoral artery. Percutaneous veno-arterial ECMO is being used with increasing frequency in adult patients with COVID-19 and acute respiratory compromise Kowalewski, et al. [2,3]. ECMO therapy during the pandemic appeared to benefit intensive care unit (ICU) patients with ARDS. It is reflected in the decrease in hospital mortality compared to the patients who received conventional oxygen therapy Cho, et al. [4]. Since this approach is relatively new and advanced, there is limited data to ensure the safety of critically ill patients during ECMO use Ramanathan, et al. [5]. The most common method of placing a patient on ECMO involves introducing large cannulas into the femoral vessels in a percutaneous fashion. The placement of an ECMO cannula into the common femoral artery creates a high likelihood of obstructing blood flow distal to the cannula, putting the patient's lower extremity at risk for tissue ischemia Migliari, et al. [6,7] described the commonly used cannulation technique that allows a portion of the ECMO blood flow to be directed past the main arterial ECMO cannula with a smaller distal perfusion cannula directed down the leg in order to provide blood flow, which creates the best chance to keep the extremity perfused. Even in this case there is a high likelihood the patient is vasoconstricted due to vasopressor use, and tissue ischemia of the leg is still possible Migliari, et al. [6]. Tissue ischemia due to arterial occlusion is an emergency that requires early recognition and intervention in order to correct successfully. Severe ischemia of lower extremities could result in necrosis of the tissue and possible compartment syndrome Foltan, et al. [8]. The subjectivity of assessing perfusion to the extremities when using ECMO, along with the intermittent nature of the assessments themselves could lead to a situation where extremity ischemia is either missed completely, or its recognition is delayed. To prevent or resolve emerging lower extremity ischemia, near-infrared spectroscopy (NIRS) oximetry was introduced to monitor the blood flow in the lower extremities Patton Rivera, et al. $[9,10]$. The monitors use NIRS, enabling them to measure tissue oxygenation at a depth of several centimeters, as well as penetrate bone in order to directly measure brain oxygenation during cardiac surgery Scheeren, et al. [11]. Despite this, the NIRS monitors are being used on the lower 
extremities of patients who are cannulated for ECMO through the femoral arteries. The hope is that the NIRS oximetry monitor alerts the clinician to a tissue desaturation in the lower extremity in real time, potentially identifying an arterial occlusion. This would provide for a more objective measure of lower extremity perfusion than bedside assessments and provide an opportunity for earlier intervention on the affected extremity. We conducted a study Feng et al. [12] to retrospectively review the electronic health records (EHR) of this population in order to correlate NIRS oximetry values with and without the incidence of lower extremity ischemia. The use of NIRS oximetry for the purpose of early detection of lower extremities ischemia would be a topic requiring education on the part of a variety of hospital staff. Hypothetically, a sudden decrease in NIRS oximetry values would precede an ischemic condition of the lower extremity.

\section{References}

1. (2020) World Health Organization. Clinical management of severe acute respiratory infection (SARI) when COVID-19 disease is suspected. Interim guidance. Pediatria \& Medycyna Rodzinna 16(1): 9-26.

2. Kowalewski M, Fina D, Słomka A, Raffa GM, Martucci G, et al. (2020) COVID-19 and ECMO: the interplay between coagulation and inflammation-a narrative review. Critical Care 24(1): 205

3. Ma X, Liang M, Ding M, Liu W, Ma H, et al. (2020) Extracorporeal Membrane Oxygenation (ECMO) in Critically Ill Patients with Coronavirus Disease 2019 (COVID-19) Pneumonia and Acute Respiratory Distress Syndrome (ARDS) Medical Science Monitor 26.

4. Cho HJ, Heinsar S, Jeong IS, Shekar k, Li Bassi, et al. (2020) ECMO use in COVID-19: lessons from past respiratory virus outbreaks-a narrative review. Critical Care 24(1).
5. Ramanathan K, Antognini D, Combes A, Paden M, Zakhary B, et al. (2020) Planning and provision of ECMO services for severe ARDS during the COVID-19 pandemic and other outbreaks of emerging infectious diseases. The Lancet Respiratory Medicine 8(5): 518-526.

6. Migliari M, Marcolin R, Avalli L, Bombino M (2014) Percutaneous Cannulation: Indication, Technique, and Complications. ECMO-Extracorporeal Life Support in Adults 37-48.

7. Tramm R, Ilic D, Davies AR, Pellegrino VA, Romero L, et al. (2015) Extracorporeal membrane oxygenation for critically ill adults. Cochrane Database of Systematic Reviews 1(1).

8. Foltan M, Philipp A, Göbölös L, Holzamer A, Schneckenpointner R, et al. (2019) Quantitative assessment of peripheral extremity perfusion using a modified distal arterial cannula in venoarterial ECMO settings. Perfusion 34(6): 503-507.

9. Patton-Rivera K, Beck J, Fung K, Chan C, Beck M, et al. (2018) Using near-infrared reflectance spectroscopy (NIRS) to assess distal-extremity perfusion on venoarterial (V-A) extracorporeal membrane oxygenation (ECMO) patients with femoral cannulation. Perfusion 33(8): 618-623.

10. Von Segesser LK, Berdajs D, Abdel-Sayed S, Ferrari E, Halbe M, et al. (2018) New, optimized, dual-lumen cannula for veno-venous ECMO. Perfusion 33(1): 18-23.

11. Scheeren TWL, Schober P, Schwarte LA (2012) Monitoring tissue oxygenation by near infrared spectroscopy (NIRS): background and current applications. Journal of Clinical Monitoring and Computing 26(4): 279287.

12. Feng F, Owen JD, Manish B, Ewing K, Countryman N (2021) Detecting extremity ischemia due to extracorporeal membrane oxygenation cannula placement with near-infrared spectroscopy. International Journal of Nursing and Health Care Science. 